\title{
Do feminismo aos seus plurais...
}

História oral, feminismo e política.

PATAI, Daphne.

São Paulo: Letra e Voz, 2010.

O século XX é, por muitos, considerado o "século das mulheres" e, especialmente, do feminismo. Ainda que os fundamentos desse movimento remontem ao século XIX, tal assertiva é corroborada por Heloisa Buarque de Hollanda ao afirmar que as conquistas políticas e sociais, somadas à expansão no mercado de trabalho e no campo cultural, deram visibilidade ao protagonismo das lutas feministas.' Tais lutas ganharam especial representatividade a partir das revoltas de 1968 e ao longo da década de 1970. Nesse momento, a desmistificação da castidade, os contraceptivos, as possibilidades de exercício do prazer e da sexualidade, reinvidicados pela revolução sexual, podem ser sintetizados pelo lema "o pessoal é político". 
Atualmente é bastante temerária a tarefa de definir precisamente uma única feição ao feminismo, uma vez que tanto sua pluralidade como a legitimidade de seu ativismo político são reconhecidas especialmente em meios acadêmicos. Tal complexidade faz com que as reflexões apresentadas por Daphne Patai em História oral, feminismo e política sejam muito contemporâneas e pertinentes.

Daphne Patai é professora de Língua, Literatura e Cultura na Universidade de Massachusetts, EUA. Dedicou-se, durante a década de 1980 e meados de 1990, ao estudo da literatura brasileira e aos women's studies. Atualmente assume uma postura crítica em relação ao que considera "uma imposição da agenda política feminista em meio acadêmico". Diz que ainda pensa o feminismo, mas contesta os women's studies por assumirem posturas excessivamente políicas, tal qual qualquer outro curso ou programa. Para a autora, que escreve diretamente a respeito de programas e universidades dos Estados Unidos, esse elemento depõe contra a potencialidade e o caráter inovador que o campo tinha a princípio.

História oral, feminismo e política é uma coletânea de textos escritos em momentos distintos que partem, porém, de uma base comum. Durante a década de 1980, Patai desenvolveu uma série de entrevistas com mulheres de diferentes grupos sociais e culturais no Brasil, mais precisamente na região Nordeste e no Rio de Janeiro. A pesquisa foi feita a partir da coleta de testemunhos com a intenção declarada de "dar voz" às mulheres. Esse trabalho, publicado na época sob o nome de Brazilian Women Speak: Contemporary Life Stories e ainda inédito no Brasil, engendrou uma série de questionamentos sobre as implicações do engajamento feminista e de questões éticas relacionadas à prática da história oral que, para a autora, possui uma forte conotação política. Os textos oriundos dessas preocupações foram reordenados e são agora apresentados na forma de ensaios provocativos, resultantes de um longa trajetória como professora, escritora e ser humano, segundo as palavras de Patai (p. 18).

O livro é composto de oito ensaios que, mesmo escritos separadamente, dialogam entre si no que concerne aos temas anunciados no título. Esses se entrecruzam delineando o pensamento inquietante - e por vezes radical da autora. Patai não se demora em definir conceitos, privilegiando o estabelecimento de um diálogo direto com o leitor, inquirindo-o a posicionar-se em relação ao que é apresentado.
O texto de abertura chamado "Construindo um eu: uma história oral de mulheres brasileiras" resulta da introdução do trabalho Brazilian Women Speak. Apresenta perspectivas iniciais sobre como Patai pensa a história oral e, ao mesmo tempo, determina as balizas de discussões que serão tecidas posteriormente.

No que se refere aos usos da história oral, podemos perceber uma série de preocupações éticas que emergem do contato com as fontes. Para a autora, que não esclarece exatamente o tratamento dado a esses depoimentos ou mesmo se suas intencionalidades como pesquisadora vão além da coleta de entrevistas, não se pode pensar um trabalho acadêmico a partir de depoimentos em um contexto de generalizações, uma vez que as especificidades do método centram-se justamente na singularidade das experiências, na riqueza de cada depoimento e na intersecção das subjetividades envolvidas: a da entrevistadora e a da entrevistada. Acredita que não se pode conhecer a história de todos aqueles que permanecem em silêncio e que encarar as histórias pessoais como representativas de algo é uma suposição corriqueira. Nesse aspecto contrapõe diretamente (mesmo que de forma involuntária) Alessandro Portelli, que aponta o imediatamente contrário ao sugerir que a representatividade nas histórias de vida se dá justamente em sua capacidade de ser única e agrupar as possibilidades de uma época ou mesmo através de sua construção textual, uma vez que os relatos podem ser compreendidos também como manifestações de estruturas de discursos definidos e aceitos socialmente. ${ }^{2}$ Além disso, Patai alerta para o estabelecimento de uma relação de poder que formata as duas personagens do processo, uma vez que o status acadêmico do pesquisador acaba por autorizálo a definir o que é pertinente ou não para os fins de sua pesquisa. Por outro lado, as narrativas, uma vez consideradas como um processo de recontrução de si, acabam sendo fugidias a objetivos preestabelecidos. Eis por que Patai defende a ideia de autonomia das narrativas e sugere discutir possibilidades de coautoria em trabalhos acadêmicos. Questiona se o narrador/ a, ao fornecer o material fundamental para a confecção dos trabalhos, não teria portanto direito autoral e mesmo financeiro sobre as possíveis publicações oriundas de seu depoimento. Esse ponto, no entanto, deixa algumas lacunas, uma vez que, na prática da história oral, os depoimentos são fontes de pesquisa e reflexão. Não são, no entanto, as únicas fontes resultantes de narrativas, afinal documentos escritos, jornais, 
cartas e relatos também possuem autoria. Nesse caso, a coautoria também se aplicaria? Qual seria a atitude ética a ser tomada?

Tais preocupações são desenvolvidas no ensaio seguinte: "Problemas éticos de narrativas pessoais, ou, quem vai ficar com o último pedaço do bolo?". Nesse, publicado originalmente em 1987, a autora reitera suas preocupações éticas, questionando sobre o sentido dos trabalhos acadêmicos para aqueles que prestaram depoimentos e ofertaram suas histórias de vida. Além do referido comprometimento com os entrevistados, o texto pondera o teor político dos trabalhos baseados em histórias de vida sob a perspectiva feminista. Isso porque a falta de uma metodologia adequada e bem definida implicaria, muitas vezes, a apropriação e a utilização das histórias de mulheres para fins próprios, desconsiderando os interesses das depoentes. Tal atitude reproduziria, segundo Patai, um paradigma social dominante, pois, em vez de contestá-lo, estaria reiterando-o, já que a mulher continuaria a ser usada como um meio. Esse ponto também pode ser considerado bastante polêmico, uma vez que, além de pressupor a falta de métodos adequados na prática da história oral, não possibilita uma reflexão apurada acerca do uso das fontes em pesquisas acadêmicas. Por fim, é bastante frágil um argumento que tenta desqualificar o caráter político de trabalhos ciêntíficos, pois, conforme anunciado no início desta resenha, o pessoal é político. Além disso, selecionar entrevistados, elaborar perguntas e elencar a abordagem de diferentes grupos sociais, com a finalidade de "dar voz aos silenciados", não implicaria também um intuito político? Essa discussão é posteriormente retomada no ensaio "História oral e feminismo: uma revisão crítica", escrito em 2008. Esse trata das características de uma pesquisa baseada na oralidade, cujo engajamento político era assumidamente feminista. Uma das problemáticas apresentadas é justamente a dificuldade em se definirem campos acadêmicos por interesses políticos e de militância, sendo essa apontada como uma fragilidade dos estudos da mulher que, para Patai, politizou excessivamente a prática acadêmica, conforme podemos perceber em "O que há de errado com os Estudos da Mulher?". Ao falar sobre os estudos da mulher (women's studies) como um campo acadêmico nos Estados Unidos, a autora tece uma crítica mordaz ao que chama de jogos feministas, apresentando sua decepção perante um "sonho utópico" que se transmutou em "pesadelo distópico". Patai ironiza diferentes aspectos da agenda feminista, alegando a existência de policiamento ideológico, aliciamento político e rejeição irrefletida de qualquer trabalho ou prática atribuída ao masculino. O próprio vocabuário feminista é passível de crítica por representar seu solipsismo acadêmico/político. Como exemplos, cria as seguintes siglas: TOTAL REJ, representando a "total rejeição a qualquer coisa contaminada pelo masculino" (p. 100), ou GENDERAGENDA, como a "redução de toda e qualquer questão ao gênero" (p. 100). Soa problemático, porém, que Patai esteja incorrendo naquilo que criticou anteriormente: acaba generalizando o que parece ser a sua experiência pessoal em determinado departamento. Seria suficiente para tecer uma crítica sistematizada aos women's studies?

As questões políticas relacionadas às problemáticas feministas são ressaltadas também em "Quem chama quem de subalterno?", no qual a autora critica de forma ferrenha e nominal o trabalho de Gayatri Spivak. A crítica direta gira em torno da adoção e da incorporação do conceito de subalternidade. Para Patai, esse rótulo desqualifica os depoimentos e as narrativas, delegando aos intelectuais a possibilidade de definir a validade de determinados discursos. Em uma crítica direta - e pouco usual em textos acadêmicos -, Patai se refere ao trabalho de Spivak:

por que uma intelectual esquerdista desejaria provar que um grupo de pessoas especialmente as historicamente silenciadas: as mulheres - não pode falar? Em nome de que tipo de conhecimento? Com que propósito? E o que devemos entender da tagarelice desses intelectuais que saem por aí pregando a impossibilidade de fala de outras pessoas? (p. 92)

Nesses termos, a autora argumenta a necessidade de se assumirem as fragilidades de pesquisas cujas fontes são os seres humanos. Não podemos esquecer, no entanto, que a grande maioria das fontes com as quais trabalhamos são produções humanas e que as proposições de Spivak implicam muito mais uma qualificação e politização do conceito de subalternidade que uma conformação de pessoas a uma condição de subalternos. Patai critica Spivak ao mesmo tempo que dela se aproxima ao afirmar que as pretensões políticas e os compromissos devem ser explícitos e possibilitar a percepção do outro, a partir daquilo que se faz significativo para 0 outro e não apenas para fundamentar as verdades do/a pesquisador/a. Tal discussão 
também é encontrada em "Chega do solipsismo nouveau dos acadêmicos", em que Patai inicia pontuando a necessidade de se considerarem as próprias posições e circunstâncias do pesquisador, assumindo-as, mas não as transformando no cerne das discussões. Critica também as "políticas de identidade" quando exacerbadas por criarem a quase necessidade de se autorreferendar e de narrar experiências pessoais como imperativo de um trabalho academicamente engajado. Esse posicionamento denota, segundo a autora, uma prática meramente retórica, sem grandes contribuíções intelectuais ou sociais.

As relações entre questões sociais e testemunhos de vida são o foco de "A verdade de quem? Iconicidade e exatidão no universo da literatura testemunhal", no qual Patai parte do texto guatemalteca Me llamo Rigoberta Menchú e así nació mi conciencia para problematizar a exatidão de um testemunho em oposição ao que esse pode significar coletivamente, ainda que factualmente inverídico. No caso de Menchú, trata-se de uma narrativa pessoal considerada exagerada por alguns, porém representativa de uma coletividade, uma vez que foi construída a partir das memórias da repressão vivida na Guatemala. Para a autora, essa narrativa representa a coletividade justamente por enquadrar-se em uma experiência política coletiva, porém, ao mesmo tempo, suscinta problemas éticos por possíveis distorções e invenções dos fatos narrados. Os questionamentos relacionados aos métodos da história oral e ao uso do conceito de subalternidade são aqui retomados como um alerta, já que Patai indaga em que medida o engajamento político autoriza e legitima elementos fictícios em uma narrativa. A autora sente-se interpelada a ponderar sobre a necessidade do engajamento político em detrimento da integridade e do comprometimento acadêmico.

O ensaio que encerra a obra, "A face evanescente do humanismo", sintetiza os argumentos da autora ao defender 0 reconhecimento de uma individualidade em contraposição às políticas de identidades familiares e à teoria pós-moderna. Para Patai, o engajamento político e a necessidade de reconhecimento de uma identidade feminista são formas de categorização incoerentes com um método de pesquisa que se volta aos testemunhos e às histórias de vida. Segundo a autora, a retórica pós-moderna cria a necessidade de enquadramento e valorização identitária, consequentemente, o indivíduo é valorizado apenas através de seus plurais. $O$ imperativo da identidade somado à militância política representam, para Patai, a constituição de um dogma entre aqueles que deveriam veementemente refutá-lo.

História oral, feminismo e política é, no mínimo, provocativo. Acusa o panfletário na academia, travestido em referências e conceitos rebuscados, que, para a autora, subvertem os sentidos do trabalho intelectual através de uma escrita direta, acusativa, sem meandros e, ironicamente, panfletária. O radicalismo de Patai e mesmo a ousadia em publicar textos representativos de posicionamentos em diferentes momentos, muitos dos quais a autora assume desacordo, transformam-se em um vívido convite para (re)pensarmos nossa prática acadêmica e reiterarmos a máxima de que o pessoal é, sim, político, afinal, ao assumir uma postura crítica em relação a um feminismo engajado, inquirir sobre a necessidade de métodos de pesquisa éticos e alertar sobre a confluência entre os objetivos intelectuais e políticos, ponderando-os como problemáticos, a autora, certamente, assume uma opção política no fazer acadêmico. A coletânea de Daphne Patai tem, finalmente, 0 mérito de inspirar-nos ao exercício da autocrítica e da reavaliação cotidiana de nossas práticas e posicionamentos teóricos, políticos e, já anunciara Aristóteles, indissociáveis.

\section{Notas}

' Heloisa Buarque de HOLLANDA, 2011.

${ }^{2}$ Alessandro PORTELLI, 1996.

\section{Referências}

HOLLANDA, Heloisa Buarque de. Feminismos contemporâneos: uma introdução. Disponível em: <http://www.heloisabuarquede hollanda.com. br $/ ? p=660 \& c a t=3>$. Acesso em: 12 jan. 2011.

PORTELLI, Alessandro. "A filosofia e os fatos: narração, interpretação e significado nas memórias e nas fontes orais". Tempo, Rio de Janeiro, v. 1, n. 2, p. 59-72, 1996.

Caroline Jaques Cubas $\square$ Universidade do Estado de Santa Catarina 